\title{
Correlation between Cognitive Functions and Motor Coordination in Children with Different Cognitive Levels
}

\author{
Pietro Luigi Invernizzi ${ }^{*}$, Matteo Crotti $^{2}$, Andrea Bosio ${ }^{3}$, Raffaele Scurati ${ }^{1}$, Nicola Lovecchio ${ }^{1}$ \\ ${ }^{1}$ Department of Biomedical Sciences for Health, Università degli Studi di Milano, Milano, Italy \\ ${ }^{2}$ School of Exercise Sciences, Università degli Studi di Milano, Milano, Italy \\ ${ }^{3}$ Human Performance Laboratory, Mapei Sport Centre, Olgiate Olona, Italy \\ Email: *pietro.invernizzi1@unimi.it
}

How to cite this paper: Invernizzi, P. L., Crotti, M., Bosio, A., Scurati, R., \& Lovecchio, N. (2018). Correlation between Cognitive Functions and Motor Coordination in Children with Different Cognitive Levels. Advances in Physical Education, 8, 98-115.

https://doi.org/10.4236/ape.2018.81011

Received: December 21, 2017

Accepted: February 10, 2018

Published: February 13, 2018

Copyright $\odot 2018$ by authors and Scientific Research Publishing Inc. This work is licensed under the Creative Commons Attribution International License (CC BY 4.0).

http://creativecommons.org/licenses/by/4.0/

\begin{abstract}
Cognitive development is related with central nervous system maturation and plays a crucial role for the definition of executive functions such as movement imagination, movement planning and problem-solving. In particular, executive functions are required during complex interactions between players/environment and are also fundamental for motor skills coordination. Although the complex interaction between cognitive and physical outcomes was recognized by several authors, few studies examined the magnitude of the relation between executive functions and motor development according to different stages of cognitive maturation. Thus the aim was the assessment of the relationships between motor skills coordination and executive functions in children with different cognitive level. Ninety healthy male participants were involved in the study where children affected by Down syndrome were, also, recruited. The participants were divided into three groups according to classification of Piaget: concrete, formal operational groups and Down syndrome individuals. Executive functions were assessed using a validated computerized battery tests while motor skills was evaluated using the Körperkoordinations Test für Kinder. Analysis of variance by ranks (Kruskal-Wallis nonparametric test) and Mann-Whitney U pairwise comparisons with Dunn's correction for multiple contrasts were applied to assess the differences concerning the two kinds of outcome. The Pearson product-moment correlation coefficient was used to calculate the correlation between physical performance and the outcomes of the cognitive tests. A Spearman correlation was used to analyze the data when the assumption of normality was violated. The three groups showed differences in both executive functions and motor coordination outcomes. The highest number of significant correlations was found in the formal operational group (correlation coefficients ranging between -0.999 and
\end{abstract}


-0.520 , and between 0.970 and 0.759 , all $p$ values $<0.05$ ) while a small number of correlations were found in the concrete operational group (correlation coefficients equal to $-0.527,-0.461,-0.436$ and 0.468 , all $p$ values $<0.05$ ). No correlations between executive function and motor coordination were found in Down syndrome group. High executive function seems to affect the coordination skills.

\section{Keywords}

Motor Skills, Piaget, KTK, Executive Function, Down's Syndrome

\section{Introduction}

The cognitive theory of the human development (Piaget \& Inhelder, 1969) defined the stages of cognitive outcomes during the growth path on the basis of the meaning given to the action and on the basis of the adaptive strategies resulting from the interaction between individual and the environment (Beilin \& Fireman, 1999). In particular, the cognitive outcomes have been described as a progression through sensorimotor, preoperational, concrete operational and formal stages (Kushner et al., 2015; Piaget \& Inhelder, 1969). More precisely: 1) the sensorimotor stage (age between 0 and 2 years) involves a progressive exploration and assimilation of external reality through the use of senses; 2 ) the preoperational stage (age between 2 and 6 years) is characterized by a selective attention that allows the progressive self-recognition and the consciousness about differences from the others even if the ability to project the own image in the virtual space where the action will take place is still poor (Garon et al., 2008); 3) the concrete operational stage (age between 7 and 11 years), instead, is characterized by mental connections between words and movements that improve the ability to use the conceptual and the anticipatory thinking of an action; 4) the formal operational stage (age between 12 and 18 years) is the period of life when the individual accomplishes inferential reasoning skills, conceptual thinking and a systematic approach to the problems/task, including motor tasks (Kushner et al., 2015).

The objective quantification of cognitive outcomes is hard to realize and is indirectly assessed using the concepts of executive functions (EF) (Best \& Miller 2010). Indeed, the EF are recognized (Diamond, 2013) as expressions of the cognitive development and as processes that control the action or attention toward a target such as the adaptive reaction to a new problem-solving situation (Diamond, 2013). In other words, the EF is an "umbrella term" that involves the complex cognitive processes required to perform novel or difficult goal-directed tasks (Hughes \& Graham, 2002): development of a plan of action sequences and holding a mental representation of a task through working memory (Welsh \& Pennington, 1988). In particular, inhibition of input, working memory, shifting of attention and planning are the most important outcomes of EF (Best et al., 
2009).

In practice, considering the human movements the EF are based on the ability to plan the action before the realization and the ability to predict the potential effects of specific actions.

It is well known that EF undergo a progressive improvement in healthy children during growth (Best \& Miller, 2010; Rigoli et al., 2012) while in individuals with mental retardation the development of EF is severely impaired (Cha \& Merrill, 1994; Hartman et al., 2010). In particular, these impairments within the EF become evident in: 1) deficit in inhibition processes; 2) motor control characterized by haste, stereotype and poor accuracy; 3) cognitive inertia that delays the possibility to perform a rapid response after an input; 4) reduced attentive span or working memory (short term memory) that does not allow to manipulate information in a conscious manner; 5) scanty utilization of previous experiences in order to solve problems and to plan actions; 6) inability to shift the attention to recognize changes in the actual context and the consequent inability to respond in a correct manner to the new task (Bergen \& Mosley, 1994; Merrill et al., 1994).

The outcomes of EF (Posner, 1993) and the relation with physical activity have been studied in humans of different ages (Hartman et al., 2010; Hotting \& Roder, 2013; Ma, Le Mare, \& Gurd, 2015; Oberer et al., 2017; Piek et al., 2004; Rigoli et al., 2012). In particular, the relationships between motor skills coordination (MSC) and EF was take into account because the MSC are aspect of the human movements that improve during growth (Vandendriessche et al., 2011; Vandorpe et al., 2011) and are strictly dependent up on the central nervous system maturation and its neural plasticity (Berlucchi, 2002; Berlucchi \& Buchtel, 2009; Jones, 2000). Indeed, several experts consider the EF and MSC as influenced by the same mental processes: both are promoted by various stimuli coming from the environment, involve the interaction between performer and active elements of the context (Barenberg et al., 2011; Van de Weijer-Bergsma et al., 2015), take advantage from previous experiences (amount of stimuli received in the past) and depend on the individual maturation (Magill, 1988). Moreover, the processes of problem-solving and imagination of action, based on the perception and comprehension of multiple aspects of a motor task, are distinctive outcomes of learning and human intelligence (Chi \& Glaser, 1985; Sternberg, 1984). Thus, we can state that the development of the central nervous system affects motor tasks that, as an iterative process, is expression of cognitive function (Piaget \& Inhelder, 1969) and metacognition (Dewey et al., 2002; Flavell, 1979). Consequently, the presence of cognitive deficits could have negative effects on motor skills outcomes (as found by Hartman et al., 2010 in children aged between 6 12 years) and strong differences from healthy peers about cerebellum and pre-frontal cortex functions (Piek et al., 2004; Wassenberg et al., 2005).

This could be observed in people with Down Syndrome (DS) whose cognitive age largely differs from the chronological age (Breckenridge et al., 2013). Indeed, 
DS is the most widespread cause of intellectual disability where low intellectual quotient values correspond to mild-to-moderate mental impairment (Silverman, 2007; Weijerman \& de Winter, 2010) and where the developmental stages described by Piaget (Cornish et al., 2007) cannot be applied (Breckenridge et al., 2013; Kushner et al., 2015).

Although the relation between MSC and academic achievements (Hillman et al., 2009; Hillman et al., 2011; van der Fels et al., 2015) such as the relationship between motor coordination and EF (Piek et al., 2004; Wassenberg et al., 2005) had been studied, to the best of our knowledge, no studies have investigated the relationship between MSC and EF taking into account the development stages proposed by Piaget. Indeed, it is opinion of the authors that a general partition of development stages, largely recognized (as recently reviewed Kushner et al., 2015), represent a very practical tools to define children in real situations (not in lab environment or in clinical assessment) such as the school context.

Thus, the aim of this study was to investigate the correlations between EF and MSC in three groups belonging to different developmental stages and with different cognitive conditions. In particular, our research considered two groups (concrete and formal stages, respectively) and a third sample represented by individuals with DS.

\section{Methods}

\subsection{Participants}

Ninety male children and pre-adolescents from northern Italy were freely recruited in schools and in non-profit associations for disabled persons over a period of 4 months during the scholar year (Table 1). All participants were divided in three groups according to the cognitive development classification proposed by Piaget (Kushner et al., 2015; Piaget \& Inhelder, 1969). The parents (or legal guardians) of each participant signed the informed consent after receiving a detailed explanation of the procedures and possible risks.

The study was conducted in accordance with the declaration of Helsinki and both participants and parents were informed that the involvement in the study could be interrupted at any time. The study protocol met the current ethical standards in sports and exercise research.

Before the beginning of the study, children and adolescents were examined by a clinician who assessed their general health and the absence of neurological and

Table 1. Anthropometric characteristics about the three groups (Mean \pm SD).

\begin{tabular}{cccccc}
\hline \multirow{2}{*}{ Group } & Participants & Age & Height & Weight & BMI \\
\cline { 2 - 6 } & $(\mathrm{n})$ & $($ years $)$ & $(\mathrm{m})$ & $(\mathrm{kg})$ & $\left(\mathrm{kg} \cdot \mathrm{m}^{-2}\right)$ \\
\hline Concrete operational & 30 & $7.1 \pm 0.4$ & $1.34 \pm 0.1$ & $31.9 \pm 4.6$ & $17.9 \pm 2.9$ \\
Formal operational & 30 & $12.6 \pm 0.7$ & $1.58 \pm 0.1$ & $48.8 \pm 13.5$ & $19.2 \pm 3.6$ \\
Down's Syndrome & 30 & $12.3 \pm 0.9$ & $1.40 \pm 0.1$ & $40.8 \pm 5.4$ & $20.9 \pm 3.1$ \\
\hline
\end{tabular}

BMI: Body Mass Index. 
orthopedic problems. Participants with DS presented the typical DS impairments such as cardiovascular diseases and ligamentous laxity (Weijerman \& de Winter, 2010). No additional cognitive deficits were detected except the effects of DS.

\subsection{MSC Measurement}

MSC was assessed using the Körperkoordinations Test für Kinder (KTK; Kiphard \& Schilling, 2007): a valid and reliable battery test used for motor assessment in children and adolescents, with a test-retest reliability coefficient of 0.97 (Kiphard \& Schilling, 1974; Vandorpe et al., 2011) and significant correlation with other coordination tests such as the Movement Assessment Battery (correlation $\mathrm{r}=0.62, \mathrm{p}<0.05$; Cools et al., 2009).

As reported in Table 2, the KTK consists of four motor trials that involve different MSC, (intercorrelation between subtests varied from 0.60 to 0.81 ; Vandorpe et al., 2011) and ensures a good discrimination (91\%) of children with brain impairment from normal children (Kiphard \& Schilling, 1974; Kiphard \& Schilling, 2007).

\subsection{Executive Function Assessment}

The executive functions were assessed by means of three separate and independent tests appropriate to evaluate selective attention, short-term (or working) memory and the shifting of attention.

Table 2. Description of the KTK test.

\begin{tabular}{|c|c|c|}
\hline Task & Required Skill & Description \\
\hline $\begin{array}{c}\text { WB } \\
\text { walking } \\
\text { backwards }\end{array}$ & balance & $\begin{array}{l}\text { walking backwards } 3 \text { times along three balance } \\
\text { beams ( } 3 \mathrm{~m} \text { long; } 5 \mathrm{~cm} \text { high; and } 6,4.5 \text { and } 3 \mathrm{~cm} \\
\text { wide). A maximum of } 24 \text { steps (eight per trial) } \\
\text { were allowed for each balance beam. }\end{array}$ \\
\hline $\begin{array}{c}\text { MS } \\
\text { movingsideways }\end{array}$ & balance, agility & $\begin{array}{l}\text { moving on the floor using two } 5.7 \mathrm{~cm} \text { high plates } \\
(25 \mathrm{~cm} \times 25 \mathrm{~cm}) \text {. The translocation required the } \\
\text { lateral displacement using the plates to step on. } \\
\text { The number of relocations in two trials } \\
\text { of } 20 \mathrm{~s} \text { was considered. }\end{array}$ \\
\hline $\begin{array}{l}\mathrm{HH} \\
\text { hopping for } \\
\text { height }\end{array}$ & power, agility & $\begin{array}{l}\text { after a short run-up jumping from one leg over a } \\
\text { pile of steps }(60 \mathrm{~cm} \text { long } \times 20 \mathrm{~cm} \text { wide } \times 5 \mathrm{~cm} \\
\text { high), three, two or one points were awarded } \\
\text { according to the number of trials } \\
\text { successfully carried out. } \\
\text { The scores obtained by the two } \\
\text { separate legs were summed. }\end{array}$ \\
\hline $\begin{array}{c}\text { JS } \\
\text { jumpingslat }\end{array}$ & speed, balance & $\begin{array}{l}\text { jumping laterally (side by side) over a wooden bar } \\
(60 \mathrm{~cm} \text { long } \times 4 \mathrm{~cm} \text { wide } \times 2 \mathrm{~cm} \text { high) for } 15 \mathrm{~s} \text {. } \\
\text { The jumps performed in two trials were summed. }\end{array}$ \\
\hline
\end{tabular}

Reliability coefficients as reported by Vandorpe et al., 2011: walking backwards: 0.80; moving sideways: 0.84; hopping for height: 0.96; jumping slat: 0.95). 
In particular, these tests are considered a valid tool to assess cognitive outcomes in healthy children as well as in children affected by cognitive deficits (Arcia, Ornstein, \& Otto, 1991; Ballard, 1996; Conners et al., 2008; Harper \& Ottinger, 1992; Huguenin, 1997; Leark et al., 1996) and consist in: 1) visual searching performance (selective attention test, SA; Bundesen \& Bundesen, 1995; Rumelhart, 1970); 2) digit span performance (short term memory test, STM; Jarvis \& Jarvis, 1991); 3) multiple targets selection within visual-spatial stimuli, as proposed by the Toulose-Pieron test (shifting of attention test, SHA; Zazzo, 1995). See Table 3 for more details.

The cognitive tests were administered using a laptop because previous studies confirmed the use of a computer and specific software as a valid and reliable method to assess different cognitive outcomes (Budde et al., 2008; Conners et al., 2008; Englund, Decker, Woodlief, \& DiStefano, 2014; Gualtieri \& Johnson, 2006; Hanania \& Smith, 2010; Ma et al., 2015; Richardson, 2007; Van de Weijer-Bergsma et al., 2015; Yazdani et al., 2015) with high correlations (r values ranging between 0.80 and 0.93 ) between the software and standard procedure of administration (Di Nuovo, 2006; 2013).

\subsection{Procedures}

One week before the data collection all participants underwent two sessions of familiarization with the testing procedures in two different days. During the first session, the participants familiarized with the computer-based battery of tests following the indications proposed by the author (Di Nuovo, 2006; 2013). The

Table 3. Description of the executive function assessed using cognitive tests.

\begin{tabular}{|c|c|c|}
\hline Test & Description & Subtests \\
\hline $\begin{array}{l}\text { SelectiveAttention } \\
\text { (SA) }\end{array}$ & $\begin{array}{l}\text { A combination of numbers appears } \\
\text { on the screen: only one is red. The } \\
\text { participant has to press the red } \\
\text { number on the keyboard before it } \\
\text { disappears. }\end{array}$ & $\begin{array}{l}\text { NE-number of errors } \\
\text { NA-number of not-answers } \\
\text { MT_-mean response time }\end{array}$ \\
\hline $\begin{array}{l}\text { Short Term } \\
\text { Memory } \\
\text { (STM) }\end{array}$ & $\begin{array}{l}\text { A succession of numbers appears on } \\
\text { the screen and after they disappear } \\
\text { the participant has to press the same } \\
\text { succession of numbers (a). In the } \\
\text { second trial (b) the succession has to } \\
\text { be pressed in reverse order of ap- } \\
\text { pearance. }\end{array}$ & $\begin{array}{l}\text { RAa-right answers in trial } a \\
\mathrm{RAb} \text {-right answers in trial } \mathrm{b} \\
\text { TRA-total right answers }(\mathrm{a}+\mathrm{b})\end{array}$ \\
\hline $\begin{array}{l}\text { Shifting of } \\
\text { attention } \\
\text { (SHA) }\end{array}$ & $\begin{array}{l}\text { This skill consists in changing the } \\
\text { focus of the attention on different } \\
\text { targets. Participant has to find three } \\
\text { given targets among several others. } \\
\text { The targets are letters } \\
\text { in the first trial (a) and } \\
\text { figures in the second (b) }\end{array}$ & $\begin{array}{l}\mathrm{NEa} \text {-number of errors in trial a } \\
\mathrm{NAa} \text {-number of not-answers in } \\
\text { trial a } \\
\mathrm{TTa} \text {-total time for trial a } \\
\mathrm{NEb} \text {-number of errors in trial b } \\
\mathrm{NAb} \text {-number of not-answers in } \\
\text { trial b } \\
\mathrm{TTb} \text { - total time for trial b }\end{array}$ \\
\hline
\end{tabular}


second session implicated the familiarization with KTK. During the data collection, each participant was assessed alone and the same order of the subtest was maintained for all people. All participants underwent the tests in their school or in the non-profit association classroom in a familiar context. In particular, the participants with DS were assisted during the whole procedures by their educational staff persons.

\subsection{Data Analysis}

KTK was designed to evaluate the general coordination considering the results of the four motor tasks all together (Table 2). In spite of this, the sum of the single scores of the KTK trials (Raw Score, RS; arbitrary units) is used to define the level of coordination (Kiphard \& Schilling, 2007). In particular, the normalization (equalization of the level) by age and mental level as suggested by Vandorpe et al. (2011) was not applied to keep the absolute differences among groups.

The data collection was stratified according to the developmental stages: formal operational, concrete operational and subjects affected by DS.

Analysis of variance by ranks (Kruskal-Wallis nonparametric test) and Mann-Whitney U pairwise comparisons with Dunn's correction for multiple contrasts (Maxwell \& Delaney, 2004) were used to evaluate the differences between the three groups concerning MSC and EF.

The Pearson product-moment correlation coefficient was used to calculate the correlation between the RS and the outcomes of the cognitive tests. A Spearman correlation was used to analyze the data when the assumption of normality was violated. Normality of the distributions was checked using the Shapiro-Wilk test. According to Cohen (Cohen, 1988), correlations equal or higher than 0.5 were considered large, correlations between 0.5 and 0.3 were considered moderate, correlations between 0.3 and 0.1 were considered small and correlations lower than 0.1 were considered insubstantial.

Based on previous research (Di Nuovo, 2006) and considering an effect size of 0.77 (Cohen's d) a sample size of 30 individuals per group was necessary to detect significant differences between groups with alpha set at 0.05 .

Statistical analyses were conducted using the SPSS, ver. 23.0 (Chicago, IL, USA).

\section{Results}

The RS of MSC and the score of each subtest of the executive functions are reported in Table 4. The ANOVA by ranks revealed significant main effects among groups on KTK (RS: $\left.\chi^{2}(2, \mathrm{~N}=90)=68.50, \mathrm{p}=0.000\right), \mathrm{SA}\left(\mathrm{NE}: \chi^{2}(2, \mathrm{~N}=\right.$ $\left.90)=28.65, \mathrm{p}=0.000 ; \mathrm{MT}: \chi^{2}(2, \mathrm{~N}=90)=74.88, \mathrm{p}=0.000\right)$, STM $\left(\right.$ RAa: $\chi^{2}(2$, $\mathrm{N}=90)=60.72, \mathrm{p}=0.000 ; \mathrm{RAb}: \chi^{2}(2, \mathrm{~N}=90)=54.66, \mathrm{p}=0.000$; TRA: $\chi^{2}(2, \mathrm{~N}=$ $90)=66.08, \mathrm{p}=0.000)$ and SHA $\left(\mathrm{NEa}: \chi^{2}(2, \mathrm{~N}=90)=28.12, \mathrm{p}=0.000\right.$; NAa: $\chi^{2}$ $(2, \mathrm{~N}=90)=28.41, p=0.000 ;$ TTa: $\chi^{2}(2, \mathrm{~N}=90)=41.41, p=0.000 ; \mathrm{NEb}: \chi^{2}(2$, 
Table 4. Comparison of the tests outcomes among the groups.

\begin{tabular}{|c|c|c|c|c|}
\hline Test & & Formaloperational & Concrete operational & Down's Syndrome \\
\hline KTK & RS & $242.93 \pm 43.51$ & $183.77 \pm 37.07^{*}$ & $80.33 \pm 15.65^{\star \#}$ \\
\hline \multirow[t]{3}{*}{ SA } & $\mathrm{NE}$ & $0.63 \pm 0.72$ & $1.33 \pm 0.88^{*}$ & $2.07 \pm 0.98^{\star *}$ \\
\hline & NA & $0.13 \pm 0.35$ & $0.27 \pm 0.45$ & $0.40 \pm 0.50$ \\
\hline & MT & $0.69 \pm 0.17$ & $1.09 \pm 0.11^{*}$ & $1.38 \pm 0.15^{\star *}$ \\
\hline \multirow[t]{3}{*}{ STM } & RAa & $5.30 \pm 1.21$ & $3.83 \pm 0.87^{\star}$ & $2.03 \pm 0.89^{* \#}$ \\
\hline & $\mathrm{RAb}$ & $4.33 \pm 1.75$ & $2.80 \pm 0.76^{*}$ & $1.10 \pm 0.61^{* \#}$ \\
\hline & TRA & $9.63 \pm 2.43$ & $6.63 \pm 1.43^{*}$ & $3.13 \pm 1.17^{* \#}$ \\
\hline \multirow[t]{6}{*}{ SHA } & $\mathrm{NEa}$ & $0.17 \pm 0.38$ & $0.73 \pm 0.78^{*}$ & $1.33 \pm 0.96^{* *}$ \\
\hline & $\mathrm{NAa}$ & $0.10 \pm 0.31$ & $0.57 \pm 0.68^{*}$ & $1.13 \pm 0.86^{* *}$ \\
\hline & $\mathrm{TTa}$ & $43.26 \pm 8.90$ & $54.29 \pm 11.37^{\star}$ & $73.84 \pm 23.22^{\star \#}$ \\
\hline & $\mathrm{NEb}$ & $0.27 \pm 0.45$ & $0.90 \pm 0.84^{*}$ & $2.37 \pm 1.87^{* \#}$ \\
\hline & $\mathrm{NAb}$ & $0.23 \pm 0.50$ & $0.37 \pm 0.61$ & $0.43 \pm 0.63$ \\
\hline & $\mathrm{TTb}$ & $62.22 \pm 12.18$ & $70.10 \pm 14.95$ & $96.12 \pm 41.46^{* \#}$ \\
\hline
\end{tabular}

Note. SA: selective attention; STM: Short Term Memory; SHA: Shifting of attention; RS: raw score; NE: number of errors; NA: number of not-answers; MT: mean response time; RA: right answers; TRA: total right answers; TT: total time; a: trial a; b: trial b. ${ }^{*}$ different $(p<0.05)$ from Formal operational group; ${ }^{*}$ different $(p<0.05)$ from Concrete operational group (Mean \pm SD).

$\mathrm{N}=90)=30.55, p=0.000$; TTb: $\left.\chi^{2}(2, \mathrm{~N}=90)=19.35, p=0.000\right)$. Effects were not found in the number of not-answers in both SA and SHA trial with figure targets $\left(\mathrm{NA}: \chi^{2}(2, \mathrm{~N}=90)=5.39, p=0.067\right.$ and NAb: $\chi^{2}(2, \mathrm{~N}=90)=2.02, p=$ 0.364 , respectively).

Pairwise comparisons unveiled significant differences between groups concerning several variables.

In KTK, the formal operational group showed higher RS both with respect to the concrete operational than to the DS groups $(p=0.000)$ while the concrete operational group had higher RS compared to DS $(p<0.001)$.

In SA, the formal operational group showed lower NE and MT compared to the concrete operational ( $p=0.002$ and $p<0.001, \mathrm{NE}$ and MT, respectively) and to the DS groups $(p<0.001)$. Furthermore, the concrete operational group presented a lower NE $(p=0.007)$ and lower MT $(p<0.001)$ than DS. Additionally, groups did not differ in NA.

Significant differences between groups were found in STM, which concerns the task of remembering the largest amount numbers appearing on the screen either in sequential and in inverted order. RAa, RAb and TRA of the formal operational group were higher compared to the other groups $(p<0.001)$, as well as the concrete operational participants better performed than participants affected by DS $(p<0.001)$.

Finally, in SHA which relates to the ability in changing the focus of the attention along tasks having letters (a) or figures (b) as targets, the formal operational group displayed fewer errors, fewer not-answers and less time to complete the task when letters are targets, compared to the other groups (NEa: $p=0.002$ and 
$p<0.001$; NAa: $p=0.001$ and $p=0.000$; TTa: $p<0.001$ and $p=0.000$; concrete and DS groups, respectively). In addition, when figures are targets, they showed a lower number of errors compared to the concrete operational and DS groups (NEb: $p<0.001$ and $p<0.001$, respectively) and less time to complete the task (TTb: $p<0.001$ ) compared to DS. Similarly, the concrete operational grou $p$ better performed than participants affected by DS in NEa $(p=0.015)$, NAa $(p=$ $0.008)$, TTa $(p<0.001)$, Neb $(p=0.001)$ and TTb $(p=0.009)$.

Large correlations were found between RS and all the executive functions outcomes in the formal operational group with correlation coefficients ranging between -0.999 and -0.520 , and between 0.970 and 0.759 (all $p$ values $<0.05$ ) (Table 5). Differently, only four significant correlations were found between RS scores and executive functions outcomes in the concrete operational group (Table 5) comprising a large correlation between RS and number of errors in the selective attention test $(\rho=-0.527, p$-value $=0.003)$, a moderate correlation between RS and number of not-answers $(\rho=-0.436, p$-value $=0.016)$ and mean response time $(\rho=-0.461, p$-value $=0.010)$ in the selective attention test and a moderate correlation between RS and right answers in trial a in the short term memory test $(\rho=0.468, p$-value $=0.009)$.

No correlations were found in the group affected by DS.

\section{Discussion}

The main findings of this study were the significant correlations between MSC

Table 5. Correlation between KTK raw scores and the outcomes obtained in the cognitive tasks.

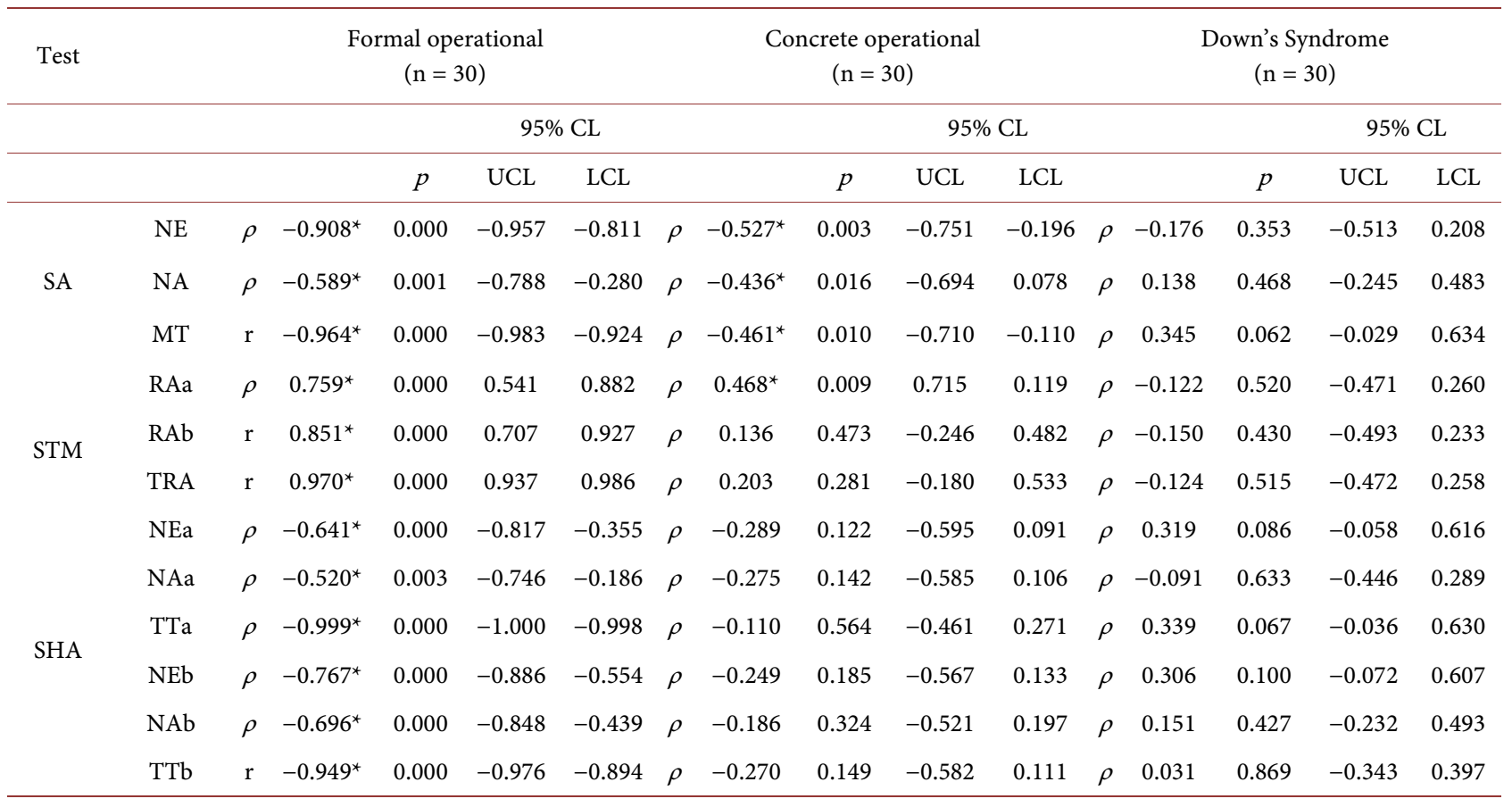

Note. r. Pearson's correlation; $\rho$. Spearman's correlation; $p$. value of inferential statistical analysis. SA: selective attention; STM: Short Term Memory; SHA: Shifting of attention; RS: raw score; NE: number of errors; NA: number of not-answers; MT: mean response time; RA: right answers; TRA: total right answers; TT: total time; a: trial a; b: trial b. ${ }^{\star} p<0.05$. 
and the EF in the formal operational groups and partially in the concrete operational group. As expected, the formal operational group presented better performances in the KTK and in the EF tests compared to the other groups. Despite their young age, the concrete operational group obtained better results in the KTK and in the executive functions tests compared to the DS group. This is in line with previous literature which clarified that people with intellectual disabilities present a compromised motor skills (Hartman et al., 2010), delay in development of coordination and cognitive function (Breckenridge et al., 2013).

\subsection{MSC and SA}

The correlations between RS and SA (Table 5) suggests that the most coordinated individuals in formal and concrete operational groups performed the cognitive trials using a shorter period of time and presenting less omissions of answers and errors compared to the less coordinated peers. This relationship supports the hypothesis about a close link between motor proficiency and the capacities of vigilance, responsiveness and visual reaction time (van der Fels et al., 2015). Furthermore, it is possible to presume, as defined by Piek et al. (2014) where the attention deficits were correlated with motor problems, that the subjects presenting low levels of coordination hesitated to make a decision because they were poorly focused on the task performance and more susceptible to distractions (Myer et al., 2013). The ability to carry out a physical or a cognitive task quickly and without haste is based on the ability to inhibit the un-relevant stimuli coming from the environment. Indeed, the formal operational group showed higher correlation than the others because the inhibitory ability improves during the concrete operational stage but reaches the stabilization during the formal stage (Diamond, 2013).

Conversely, cognitive inertia, a typical feature of mental retardation, is responsible for hasty performance that leads to imprecision and a high amount of errors during actions (Ellis \& Dulaney, 1991): particularly in balancing ability (Rigoli et al., 2012; Wassenberg et al., 2005).

\subsection{MSC and STM}

STM was positively correlated with RS within the formal operational group while the concrete operational one showed significant correlation only with the first task (recall a forward sequence of numbers) and none about the inverted sequence recall task.

This could represent an interesting phenomenon: remembering a sequence of information and immediately rephrase as inverted sequence could be difficult for 7-years old children. Our finding suggested that managing a dual task is a difficult performance for children belonging to a concrete operational stage. Similarly, walking backwards while maintaining the balance on a balance beam represents a difficult dual task for 7-years old children (balance and backward walk).

The difficulties in performing a dual task might be linked to the fact that the 
transition from intuitive to logic thinking (Piaget \& Inhelder, 1969) is still in a premature phase in 7-years old children.

In advance, the absence of correlation between coordination level and short memory in subjects affected by DS suggests that the attentional resources, that consist in the ability to maintain concentration and vigilance during a timespan, are not sufficiently developed, thus influencing the ability to recall a sequence of information (Howieson \& Lezak, 2002).

\subsection{RS and SHA}

A relation between MSC and SHA outcomes was observed only in the formal operational group. STM and SHA improve later than the capacity of inhibitory response that is linked to SA. In fact, SA evaluation tests are based on visual search and on response promptness: in these cases the performances were not related to the intellectual capacity of problem-solving (Bundesen \& Bundesen, 1995).

On the other hand, the digit span task and the SHA (based on multiple search involving verbal and visual-spatial stimuli where the attentive focus changes continuously) are related to the difficulties in the attentive task and to the inability to complete cognitive tasks. Furthermore, lack of relations between RS and SHA should be particularly evident in people with mental retardation. The cognitive inertia obstructs their mental flexibility and therefore, individuals cannot shift the focus in a proper manner when the task requires changes to be successfully accomplished (Ellis \& Dulaney, 1991).

\subsection{Schematic Representation of Relationship between Development Stages and Executive Function}

The results of the study are summarized in Figure 1 that shows a progressive integration between cognitive and MSC within each cognitive developmental stage. In particular, in the concrete and formal operational groups the outcomes become progressively more conscious; while in the group affected by DS the motor interpretation seems to be due to spontaneous adaptation. The considerations concerning the participants with intellectual disabilities disagree with Hartman et al. findings (2010). The MSC test used in the present study is mainly based on performance rather than on the process of skill sequences: this may have affected the results of the present study and might explain the differences.

\subsection{Practical Applications}

Questions, hypothesis, explanations, summarizations and prediction could represent useful strategies to better integrate cognitive approaches and motor tasks offering the chance to anticipate solutions and to solve new motor requirements in normally psycho-physically developed children (Hotting \& Roder, 2013; Palinscar \& Brown, 1984).

Physical activities based on problem-solving and on situational experience could stimulate anticipatory and reflective processes that could guarantee 


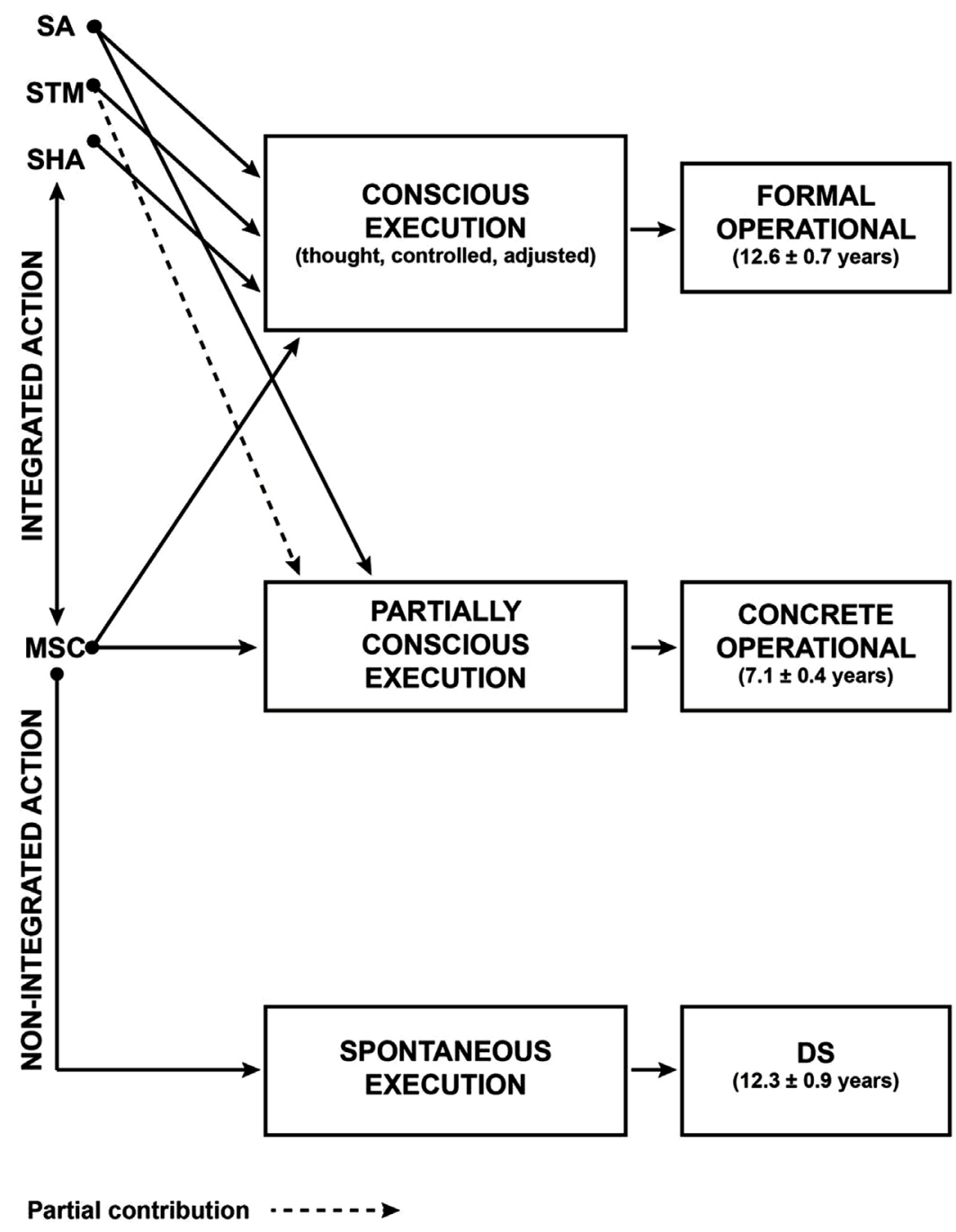

Figure 1. Schematic representation of relationships between development stages, motor skills coordination and executive function. SA: selective attention; STM: Short Term Memory; SHA: Shifting of attention; MSC: motor skills coordination; DS: Down's Syndrome.

further development in motor control and learning (Karpov \& Gindis, 2000). In the present study, this does not seem to be valid for DS.

\subsection{Limitations}

Limitations of the present study include the recruitment of only male participantsand from a specific geographic area. It cannot be excluded the presence of differences between genders especially during the pre-adolescent period where females might show an early maturation. Furthermore, each single group might not be completely representative of each human developmental stage (Piaget \& Inhelder, 1969) because of the restricted age range selected. For instance, the concrete operational stage is represented in the present study by a sample between 7 and 8 years old individuals while, according to Piaget (Piaget \& Inhelder, 1969), this stage goes from 7 to 11 years old. For these reasons and the rela- 
tively small sample, the present study can represent only a pilot study on the topic.

\section{Conclusion}

The results of our study revealed a significant relation between high level of MSC and EF only for the formal operational group and only a similar trend for the concrete operational children. New insights are pointed out and show that Piaget's stages of the cognitive development can be applied into practice only in children having a regular psycho-motor development, whereas in DS children no relationship exists between cognitive functions and coordinative abilities such as measured during testing protocol (Oberer et al., 2017). Our results are in line with previous research proving that coordinative exercise is effective to improve attention and concentration only in normally psycho-physically developed children (Budde et al., 2008; Pesce et al., 2013) and increases the understanding of the complex relation between coordinative performance and cognitive processes (Budde et al., 2008; Swagerman et al., 2015; van der Fels et al., 2015).

\section{Perspective}

Further investigation should consider the individual history of physical activity and sport practice to verify the effects of different stimuli (quantity and quality) received during a very sensitive period of cognitive development.

It could be also interesting to apply the same study protocol to female participants, as they were not included in this study, to assess the possible differences.

The combination between cognitive and motor tasks is arousing interest as it seems to have influences on specific brain areas (cerebellum, pre-frontal cortex, basal ganglia; Wassenberg et al., 2005; Piek et al., 2004) such as the hippocampus and is supposed to produce a neurogenic reserve that could be of advantage for future life requirements (Kempermann, 2008).

Improving the knowledge about the relationships between EF and MSC is an intriguing topic which may considerably improve didactic strategies which aim to improve physical literacy and therefore a conscious lifelong participation in physical activities (Whitehead, 2010).

\section{References}

Arcia, E., Ornstein, P. A., \& Otto, D. A. (1991). Neurobehavioral Evaluation System (NES) and School Performance. Journal of School Psychology, 29, 337-352. https://doi.org/10.1016/0022-4405(91)90021-I

Ballard, J. C. (1996). Computerized Assessment of Sustained Attention: A Review of Factors Affecting Vigilance Performance. Journal of Clinical and Experimental Neuropsychology, 18, 843-863. https://doi.org/10.1080/01688639608408307

Barenberg, J., Berse, T., \& Dutke, S. (2011). Executive Functions in Learning Processes: Do They Benefit from Physical Activity? Educational Research Review, 6, 208-222. https://doi.org/10.1016/j.edurev.2011.04.002

Beilin, H., \& Fireman, G. (1999). The Foundation of Piaget's Theories: Mental and Physi- 
cal Action. Advances in Child Development and Behavior, 27, 221-246. https://doi.org/10.1016/S0065-2407(08)60140-8

Bergen, A. M., \& Mosley, J. L. (1994). Attention and Attentional Shift Efficiency in Individuals with and without Mental Retardation. American Journal of Mental Retardation: AJMR, 98, 732-743.

Berlucchi, G. (2002). The Origin of the Term Plasticity in the Neurosciences: Ernesto Lugaro and Chemical Synaptic Transmission. Journal of the History of the Neurosciences, 11, 305-309. https://doi.org/10.1076/jhin.11.3.305.10396

Berlucchi, G., \& Buchtel, H. A. (2009). Neuronal Plasticity: Historical Roots and Evolution of Meaning. Experimental Brain Research, 192, 307-319. https://doi.org/10.1007/s00221-008-1611-6

Best, J. R., \& Miller, P. H. (2010). A Developmental Perspective on Executive Function. Child Development, 81, 1641-1660. https://doi.org/10.1111/j.1467-8624.2010.01499.x

Best, J. R., Miller, P. H., \& Jones, L. L. (2009). Executive Functions after Age 5: Changes and Correlates. Developmental Review, 29, 180-200.

https://doi.org/10.1016/j.dr.2009.05.002

Breckenridge, K., Braddick, O., Anker, S., Woodhouse, M., \& Atkinson, J. (2013). Attention in Williams Syndrome and Down's Syndrome: Performance on the New Early Childhood Attention Battery. The British Journal of Developmental Psychology, 31, 257-269. https://doi.org/10.1111/bjdp.12003

Budde, H., Voelcker-Rehage, C., Pietrabyk-Kendziorra, S., Ribeiro, P., \& Tidow, G. (2008). Acute Coordinative Exercise Improves Attentional Performance in Adolescents. Neuroscience Letters, 441, 219-223. https://doi.org/10.1016/j.neulet.2008.06.024

Bundesen, \& Bundesen (1995). Visual Selective Attention: A Special Issue of the Journal. Hove: Psychology Press.

Cha, K. H., \& Merrill, E. C. (1994). Facilitation and Inhibition Effects in Visual Selective Attention Processes of Individuals with and without Mental Retardation. American Journal of Mental Retardation: AJMR, 98, 594-600.

Chi, M. T. H., \& Glaser, R. (1985). Problem-Solving Ability. In R. J. Sternberg (Ed.), Human Abilities: An Information-Processing Approach (pp. 227-257). San Francisco, CA: W H Freeman \& Co. (Sd).

Cohen, J. (1988). Statistical Power Analysis for the Behavioural Sciences (2nd ed.). Hillsdale, NJ: Lawrence Erlbaum Associates.

Conners, F. A., Rosenquist, C. J., Arnett, L., Moore, M. S., \& Hume, L. E. (2008). Improving Memory Span in Children with Down Syndrome. Journal of Intellectual Disability Research, 52, 244-255. https://doi.org/10.1111/j.1365-2788.2007.01015.x

Cools, W., Martelaer, K. D., Samaey, C., \& Andries, C. (2009). Movement Skill Assessment of Typically Developing Preschool Children: A Review of Seven Movement Skill Assessment Tools. Journal of Sports Science \& Medicine, 8, 154-168.

Cornish, K., Scerif, G., \& Karmiloff-Smith, A. (2007). Tracing Syndrome-Specific Trajectories of Attention across the Lifespan. Cortex, 43, 672-685. https://doi.org/10.1016/S0010-9452(08)70497-0

Dewey, D., Kaplan, B. J., Crawford, S. G., \& Wilson, B. N. (2002). Developmental Coordination Disorder: Associated Problems in Attention, Learning, and Psychosocial Adjustment. Human Movement Science, 21, 905-918. https://doi.org/10.1016/S0167-9457(02)00163-X

Di Nuovo, S. (2006). La valutazione dell'attenzione: Dalla ricerca sperimentale ai contesti applicativi. Milano: Franco Angeli. 
Di Nuovo, S. (2013). Attenzione e concentrazione-Nuova Edizione (CD-ROM). Trento: Erickson.

Diamond, A. (2013). Executive Functions. Annual Review of Psychology, 64, 135-168. https://doi.org/10.1146/annurev-psych-113011-143750

Ellis, N. R., \& Dulaney, C. L. (1991). Further Evidence for Cognitive Inertia of Persons with Mental Retardation. American Journal of Mental Retardation: AJMR, 95, 613-621.

Englund, J. A., Decker, S. L., Woodlief, D. T., \& DiStefano, C. (2014). Development and Evaluation of an Online, Multicomponent Working Memory Battery. Assessment, 21, 543-561. https://doi.org/10.1177/1073191114524016

Flavell, J. H. (1979). Metacognition and Cognitive Monitoring: A New Area of Cognitive-Developmental Inquiry. American Psychologist, 34, 906. https://doi.org/10.1037/0003-066X.34.10.906

Garon, N., Bryson, S. E., \& Smith, I. M. (2008). Executive Function in Preschoolers: A Review using an Integrative Framework. Psychological Bulletin, 134, 31-60. https://doi.org/10.1037/0033-2909.134.1.31

Gualtieri, C. T., \& Johnson, L. G. (2006). Reliability and Validity of a Computerized Neurocognitive Test Battery, CNS Vital Signs. Archives of Clinical Neuropsychology: The Official Journal of the National Academy of Neuropsychologists, 21, 623-643. https://doi.org/10.1016/j.acn.2006.05.007

Hanania, R., \& Smith, L. B. (2010). Selective Attention and Attention Switching: Towards a Unified Developmental Approach. Developmental Science, 13, 622-635. https://doi.org/10.1111/j.1467-7687.2009.00921.x

Harper, G. W., \& Ottinger, D. R. (1992). The Performance of Hyperactive and Control Preschoolers on a New Computerized Measure of Visual Vigilance: The Preschool Vigilance Task. Journal of Child Psychology and Psychiatry, 33, 1365-1372. https://doi.org/10.1111/j.1469-7610.1992.tb00956.x

Hartman, E., Houwen, S., Scherder, E., \& Visscher, C. (2010). On the Relationship between Motor Performance and Executive Functioning in Children with Intellectual Disabilities. Journal of Intellectual Disability Research, 54, 468-477. https://doi.org/10.1111/j.1365-2788.2010.01284.x

Hillman, C. H., Buck, S. M., Themanson, J. R., Pontifex, M. B., \& Castelli, D. M. (2009). Aerobic Fitness and Cognitive Development: Event-Related Brain Potential and Task Performance Indices of Executive Control in Preadolescent Children. Developmental Psychology, 45, 114-129. https://doi.org/10.1037/a0014437

Hillman, C. H., Kamijo, K., \& Scudder, M. (2011). A Review of Chronic and Acute Physical Activity Participation on Neuroelectric Measures of Brain Health and Cognition during Childhood. Preventive Medicine, 52, S21-S28.

https://doi.org/10.1016/j.ypmed.2011.01.024

Hotting, K., \& Roder, B. (2013). Beneficial Effects of Physical Exercise on Neuroplasticity and Cognition. Neuroscience \& Biobehavioral Reviews, 37, 2243-2257.

https://doi.org/10.1016/j.neubiorev.2013.04.005

Howieson, D. B., \& Lezak, M. D. (2002). The Handbook of Memory Disorders. In A. D. Baddeley, M. D. Kopelman, \& B. A. Wilson (Eds.), The Handbook of Memory Disorders (pp. 637-654). New York, NY: J. Wiley.

Hughes, C., \& Graham, A. (2002). Measuring Executive Functions in Childhood: Problems and Solutions. Children and Adolescent Mental Health, 7, 131-142.

https://doi.org/10.1111/1475-3588.00024

Huguenin, N. H. (1997). Employing Computer Technology to Assess Visual Attention in 
Young Children and Adolescents with Severe Mental Retardation. Journal of Experimental Child Psychology, 65, 141-170. https://doi.org/10.1006/jecp.1996.2357

Jarvis, P. E., \& Jarvis, C. P. (1991). A Tool to Assist in the Serial Testing of Attention as a Means of Monitoring the Effectiveness of Rehabilitation. Cognitive Rehabilitation, 9, 20-23.

Jones, E. G. (2000). Plasticity and Neuroplasticity. Journal of the History of the Neurosciences, 9, 37-39. https://doi.org/10.1076/0964-704X(200004)9:1;1-2;FT037

Karpov, Y. V., \& Gindis, B. (2000). Dynamic Assessment of the Level of Internalization of Elementary School Children's Problem-Solving Activity. In C. Lidz, \& J. G. Elliott (Eds.), Dynamic Assessment: Prevailing Models and Applications (pp. 133-154). JAI.

Kempermann, G. (2008). The Neurogenic Reserve Hypothesis: What Is Adult Hippocampal Neurogenesis Good for? Trends in Neurosciences, 31, 163-169. https://doi.org/10.1016/j.tins.2008.01.002

Kiphard, E. J., \& Schilling, F. (1974). Körperkoordinationstest für Kinder: KTK. Weinheim: Beltz Test.

Kiphard, E. J., \& Schilling, F. (2007). Körperkoordinationstest für Kinder. Weinheim: Beltz Test.

Kushner, A. M., Kiefer, A. W., Lesnick, S., Faigenbaum, A. D., Kashikar-Zuck, S., \& Myer, G. D. (2015). Training the Developing Brain Part II: Cognitive Considerations for Youth Instruction and Feedback. Current Sports Medicine Reports, 14, 235-243. https://doi.org/10.1249/JSR.0000000000000150

Leark, R. A., Dupuy, T. R., Greenberg, L. M., Corman, C. L., \& Kindschi, C. (1996). T.O.V.A. Test of Variables of Attention. Los Alamitos: Universal Attention Disorders Inc.

Ma, J. K., Le Mare, L., \& Gurd, B. J. (2015). Four Minutes of In-Class High-Intensity Interval Activity Improves Selective Attention in 9 to 11 Year Olds. Applied Physiology, Nutrition, and Metabolism, 40, 238-244. https://doi.org/10.1139/apnm-2014-0309

Magill, R. A. (1988). Critical Periods as Optimal Readiness for Learning Sport Skills. In R. A. Magill, F. L. Smoll, \& M. J. Ash (Eds.), Children in Sport (pp. 53-65). Champaign, IL: Human Kinetics Publishers.

Maxwell, S. E., \& Delaney, H. D. (2004). Designing Experiments and Analyzing Data. A Model Comparison Perspective (2nd ed.). Mahwah, NJ: Lawrence Erlbaum Associates.

Merrill, E. C., Cha, K. H., \& Moore, A. L. (1994). Suppression of Irrelevant Location Information by Individuals with and without Mental Retardation. American Journal of Mental Retardation: AJMR, 99, 207-214.

Myer, G. D., Kushner, A. M., Faigenbaum, A. D., Kiefer, A., Kashikar-Zuck, S., \& Clark, J. F. (2013). Training the Developing Brain, Part I: Cognitive Developmental Considerations for Training Youth. Current Sports Medicine Reports, 12, 304-310. https://doi.org/10.1097/01.CSMR.0000434106.12813.69

Oberer, N., Gashaj, V., \& Roebers, C. M. (2017). Motor Skills in Kindergarten: Internal Structure, Cognitive Correlates and Relationships to Background Variables. Human Movement Science, 52, 170-180. https://doi.org/10.1016/j.humov.2017.02.002

Palinscar, A. S., \& Brown, A. L. (1984). Reciprocal Teaching of Comprehension-Fostering and Comprehension-Monitoring Activities. Cognition and Instruction, 1, 117-175. https://doi.org/10.1207/s1532690xci0102_1

Pesce, C., Crova, C., Marchetti, M., Struzzolino, I., Masci, I., Vannozzi, G., \& Forte, R. (2013). Searching for Cognitively Optimal Challenge Point in Physical Activity for Children with Typical and Atypical Motor Development. Mental Health and Physical 
Activity, 6, 172-180.

Piaget, J., \& Inhelder, B. (1969). The Psychology of the Child. New York, NY: Basic Books.

Piek, J. P., Dyck, M. J., Nieman, A., Anderson, M., Hay, D., Smith, L. M., McCoy, M., \& Hallmayer, J. (2004). The Relationship between Motor Coordination, Executive Functioning and Attention in School Aged Children. Archives of Clinical Neuropsychology, 19, 1063-1076. https://doi.org/10.1016/j.acn.2003.12.007

Posner, M. I. (1993). Attention before and during the Decade of the Brain. In D. E. Meyer, \& S. Kornblum (Eds.), Attention and Performance: Synergies in Experimental Psychology, Artificial Intelligence and Cognitive Neuroscience 14th: Symposium Proceedings (pp. 343-350). Cambridge, MA: MIT Press.

Richardson, J. T. (2007). Measures of Short-Term Memory: A Historical Review. Cortex, 43, 635-650. https://doi.org/10.1016/S0010-9452(08)70493-3

Rigoli, D., Piek, J. P., Kane, R., \& Oosterlaan, J. (2012). An Examination of the Relationship between Motor Coordination and Executive Functions in Adolescents. Developmental Medicine \& Child Neurology, 54, 1025-1031.

https://doi.org/10.1111/j.1469-8749.2012.04403.x

Rumelhart, D. E. (1970). A Multicomponent Theory of the Perception of Briefly Exposed Visual Displays. Journal of Mathematical Psychology, 7, 191-218. https://doi.org/10.1016/0022-2496(70)90044-1

Silverman, W. (2007). Down Syndrome: Cognitive Phenotype. Mental Retardation and Developmental Disabilities Research Reviews, 13, 228-236. https://doi.org/10.1002/mrdd.20156

Sternberg, R. J. (1984). Toward a Triarchic Theory of Human Intelligence. The Behavioral and Brain Sciences, 7, 269. https://doi.org/10.1017/S0140525X00044629

Swagerman, S. C., de Geus, E. J., Koenis, M. M., Hulshoff Pol, H. E., Boomsma, D. I., \& Kan, K. J. (2015). Domain Dependent Associations between Cognitive Functioning and Regular Voluntary Exercise Behavior. Brain and Cognition, 97, 32-39.

https://doi.org/10.1016/j.bandc.2015.04.001

Van de Weijer-Bergsma, E., Kroesbergen, E. H., Prast, E. J., \& Van Luit, J. E. (2015). Validity and Reliability of an Online Visual-Spatial Working Memory Task for Self-Reliant Administration in School-Aged Children. Behavior Research Methods, 47, 708-719. https://doi.org/10.3758/s13428-014-0469-8

van der Fels, I. M., Te Wierike, S. C., Hartman, E., Elferink-Gemser, M. T., Smith, J., \& Visscher, C. (2015). The Relationship between Motor Skills and Cognitive Skills in 4-16 Year Old Typically Developing Children: A Systematic Review. Journal of Science and Medicine in Sport, 18, 697-703. https://doi.org/10.1016/j.jsams.2014.09.007

Vandendriessche, J. B., Vandorpe, B., Coelho-e-Silva, M. J., Vaeyens, R., Lenoir, M., Lefevre, J., \& Philippaerts, R. M. (2011). Multivariate Association among Morphology, Fitness, and Motor Coordination Characteristics in Boys Age 7 to 11. Pediatric Exercise Science, 23, 504-520. https://doi.org/10.1123/pes.23.4.504

Vandorpe, B., Vandendriessche, J., Lefevre, J., Pion, J., Vaeyens, R., Matthys, S., Philippaerts, R., \& Lenoir, M. (2011). The Korperko Ordinations Test fur Kinder: Reference Values and Suitability for 6-12 Year-Old Children in Flanders. Scandinavian Journal of Medicine \& Science, 21, 378-388. https://doi.org/10.1111/j.1600-0838.2009.01067.x

Wassenberg, R., Feron, F. J., Kessels, A. G., Hendriksen, J. G., Kalff, A. C., Kroes, M., Hurks, P. P., Beeren, M., Jolles, J., \& Vles, J. S. (2005). Relation between Cognitive and Motor Performance in 5-6 Year-Old Children: Results from a Large-Scale Cross-Sectional Study. Children Development, 76, 1092-1103. 
https://doi.org/10.1111/j.1467-8624.2005.00899.x

Weijerman, M. E., \& de Winter, J. P. (2010). Clinical Practice. The Care of Children with Down Syndrome. European Journal of Pediatrics, 169, 1445-1452.

https://doi.org/10.1007/s00431-010-1253-0

Welsh, M. C., \& Pennington, B. F. (1988). Assessing Frontal Lobe Functioning in Children: Views from Developmental Psychology. Developmental Neuropsychology, 4, 199-230. https://doi.org/10.1080/87565648809540405

Whitehead, M. (2010). Physical Literacy. Throughout the Lifecourse. New York, NY: Routledge.

Yazdani, F., Akbarfahimi, M., Hassani Mehraban, A., Jalaei, S., \& Torabi-Nami, M. (2015). A Computer-Based Selective Visual Attention Test for First-Grade School Children: Design, Development and Psychometric Properties. Medical Journal of the Islamic Republic of Iran, 29, 184.

Zazzo, R. (1995). Manuale per l'esame psicologico del bambino. Roma: Editori Riuniti. 